\title{
Is the striatum involved in passive-avoidance behavior? A commentary
}

\author{
STEPHEN POLGAR \\ Department of Behavioural Sciences, Lincoln Institute \\ Carlton, Victoria 3053, Australia \\ PAUL R. SANBERG \\ Department of Behavioural Biology, Research School of Biological Sciences \\ Canberra, A.C.T. 2600, Australia \\ and \\ ROBERT J. KIRKBY \\ Department of Behavioural Sciences, Lincoln Institute \\ Carlton, Victoria 3053, Australia

\begin{abstract}
The role of the striatum in passive avoidance (PA) behavior has been reviewed in light of recent data by Olmstead and Villablanca (1980) reporting a lack of involvement of the caudate nucleus in this behavior. Evaluation of their data revealed that a small deficit in PA was demonstrated in the caudotomized adult cat group. Similarly, our own data with kainic-acid-induced striatal lesions in rats resulted in impairments in passive-avoidance acquisition and retention. It is concluded that the striatum is involved in PA behavior, although the underlying behavioral processes that contribute to this role are not clearly understood.
\end{abstract}

Recently, Olmstead and Villablanca (1980) suggested that the striatum (caudate nucleus and putamen) was not involved in passive-avoidance learning and that previous findings of PA deficits following striatal lesions probably reflected experimental artifacts. Given that these suggestions might have serious influences on the understanding of striatal functioning, the aim of this paper was to examine critically Olmstead and Villablanca's findings in the context of the problems involved in the interpretation of changes in avoidance learning following central nervous system lesions.

\section{Olmstead and Villablanca's (1980) Study}

Olmstead and Villablanca (1980) compared the PA performance of cats, including groups with large caudate and frontal cortical lesions. Eight cats with bilateral caudate lesions were operated on as kittens (kitten BAc), while 11 others were operated on as adults (adult BAc). Initially, for two trials daily over 2 days, the animals were placed on a platform and allowed to step down without shock. After the fourth trial, an inescapable shock was delivered, and PA was assessed as a tendency for the animals on later

Paul R. Sanberg's present address is Department of Neuroscience, School of Medicine, The Johns Hopkins University, Baltimore, Maryland 21205. trials to remain on the platform up to a cutoff of $300 \mathrm{sec}$. It was found that, in comparison with other groups, the adult BAc group was significantly slower to leave the platform on Trial 1 of Day 1. The PA performance of all participating subjects was measured on three occasions, Days 1, 2, and 7 after the learning trial. It was reported that there were no significant differences between the adult BAc and other groups on the first two testing sessions. However, on Test Day 7, the adult BAc group was significantly impaired. Olmstead and Villablanca did not interpret this significant impairment in the adult BAc group as indicating a PA deficit, but they noted that since $44 \%$ of the adult BAc animals avoided according to criterion latency, this indicated that as a group the cats had acquired and retained some learning. Olmstead and Villablanca argued that the "subtle" behavioral changes in the adult BAc subjects "merely reflect some of the peculiarities in reactivity and activity" (p. 342) and concluded that "we have a strong indication of a lack of a role of the striatum in passive avoidance"' (p. 343).

Several conceptual issues are raised by Olmstead and Villablanca's conclusions.

\section{The Question of Negative Findings}

When assessing the pattern of avoidance changes as suggested by Olton (1973), it is clear that the ap- 
Table 1

Passive Avoidance Following Caudotomy

\begin{tabular}{lrrrr}
\hline & \multicolumn{4}{c}{$\begin{array}{c}\text { Percentage of Subjects } \\
\text { Not Avoiding }\end{array}$} \\
\cline { 2 - 5 } \multicolumn{1}{c}{ Retention-Extinction Trials } & N & 1 & 2 & 3 \\
\hline Combined Sham-Operated Controls & 11 & 9 & 0 & 0 \\
Adult BAc & 9 & 33 & 33 & 56 \\
\hline
\end{tabular}

Note-Data are from Olmstead and Villablanca (1980, Table 1, p. 341).

parent absence of involvement of a particular brain lesion in an avoidance task suggests crucial information concerning the behavioral role of that neural structure. Therefore, the question of Type II errors occurring in any given study should be raised. The design of Olmstead and Villablanca's (1980) study of PA involved the comparison of a relatively large number (nine) of groups, some of quite small size (ranging from five to nine subjects). The suggestion that a real, but rather small, effect might have been overlooked in the study is supported by the following comparison of the adult BAc group with the combined PA performances of the two sham-lesioned control groups used in the study (Table 1).

Inspection of Table 1 suggests two points. First, the PA task was relatively easy since no extinction or retention deficits were demonstrated by the controls by the 2 nd or 3rd day of PA testing. Second, in relation to the controls, there appears to be a tendency for the adult BAc group to be impaired on PA, this effect being most marked on the third session. Taking into account that this group initially had a significantly greater tendency to remain on the platform, it is difficult to see how the effect can be labeled as "subtle." Therefore, an alternative interpretation of Olmstead and Villablanca's (1980) findings is that large bilateral caudate nucleus lesions in adult cats result in a PA retention deficit. The effect, at least initially, appears quite small for a particularly simple task, so that a rather powerful experimental design is necessary to uncover it. The fact that there was not a $100 \%$ deficit in PA in the caudate-damaged group in no way detracts from the above interpretation. There are valid reasons, such as the almost-certain involvement of other neural systems in the task or the arbitrary nature of the criteria used to assess PA learning. Olmstead and Villablanca's criterion was that of finding an absolute deficit in PA, instead of judging performance in relation to controls.

\section{Task Parameters and Avoidance Performance. Evidence from Previous Studies Concerning the Effects of Caudate Lesions on PA}

Olmstead and Villablanca reviewed four lesion studies relating caudate nucleus lesions in adult cats to avoidance performance. Three of these studies
(Laursen, 1963; Thompson, 1959; Thompson \& Mettler, 1963) demonstrated avoidance deficits, but they were active-avoidance deficits and not relevant to the question of PA deficits (see Olton, 1973). The remaining study (Fox, Kimble, \& Lickey, 1964) reported significant deficits in caudate-damaged cats on a PA task. Olmstead and Villablanca (1980) reported that, in agreement with their results, ReyesVasquez, Zarco-Coronado, and Brust-Carmona (1978) found that 6-hydroxydopamine injections into the anteroventral caudate nuclei did not result in deficits for a PA task. However, given other reports that DA depletion does not disrupt PA but, rather, disrupts active-avoidance behavior (e.g., Cooper, Breese, Grant \& Howard, 1973; Fibiger \& Phillips, 1976; Neill, Boggan \& Grossman, 1974; Zis, Fibiger, \& Phillips, 1974), the lack of a PA deficit reported by Reyes-Vasquez et al. (1968) is not surprising. The weight of evidence suggests that, while DA apparently is not involved in PA, there are other neurotransmitter systems in the striatum, such as the cholinergic and GABAergic systems (Coyle, McGeer, McGeer, \& Schwarcz, 1978) that might well mediate PA behavior (Deadwyler, Montgomery, \& Wyers, 1972; Haycock, Deadwyler, Sideroff, \& McGaugh, 1973; Vazquez, Tellez, De La Mora, \& Brust-Carmona, 1979).

In relation to the findings concerning the effects of caudate damage on avoidance in rats, Olmstead and Villablanca (1980) draw two conclusions. The first is that the literature is quite unclear, and the second is that the behavioral findings are obscured by the artifact of damage to capsular fibers coursing through the rat's striatum.

With regard to the literature, Olmstead and Villablanca (1980) failed to distinguish between the pattern of findings concerning the different avoidance paradigms. In fact, in all the studies in the area quoted by Olmstead and Villablanca (Kirkby \& Kimble, 1968; Mitcham \& Thomas, 1972; Sanberg, Pisa, \& Fibiger, 1979; Winocur, 1974), there is a clear consensus that striatal lesions in the rat do result in PA deficits. This view has also been supported by similar findings of Glick and Greenstein (1973) in mice and Rothman and Glick (1976) in rats. The conditions under which a PA deficit has been most reliably found were for PA tasks involving the inhibition of a learned rather than a simple unpracticed response (Kirkby \& Kimble, 1968; Winocur \& Mills, 1969). In fact, the reason for the small PA deficit found by Olmstead and Villablanca (1980) and the differences between their findings and those of Fox et al. (1964) might well reflect the "unpracticed" PA paradigm chosen by Olmstead and Villablanca (1980).

Olmstead and Villablanca (1980) were justified in pointing out the possibility that damage to fibers of passage by striatal lesions in the rat complicates the interpretation of avoidance performance. However, 
they were mistaken in asserting that "to date ... there have been no adequately controlled studies for that fiber damage" (p. 343). Investigators in the area have been well aware of this complication and have attempted to control for it. For example, there have been numerous studies involving the intrastriatal injections of substances that are known to disrupt specific neurotransmitter functioning without, presumably, affecting fibers of passage, which have demonstrated the involvement of striatal systems in both active (e.g., Neill \& Grossman, 1970; Neill et al., 1974) and passive (Haycock et al., 1973; Prado-Alcala, Cruz-Morales, \& Lopez-Miro, 1980; Vazquez et al., 1979) avoidance.

In a more novel study using kainic-acid-induced lesions of the striatum, which apparently spare fibers of passage (Coyle et al., 1978), Sanberg, Lehmann, and Fibiger (1978) demonstrated PA deficits in the rat. However, in a subsequent study (Sanberg et al., 1979), some of the striatally lesioned rats also had hippocampal damage as a result of the intrastriatal kainic acid injections. While the presence of hippocampal damage in some rats may complicate the attributing of the PA deficits to the striatal pathology per se, Sanberg et al. (1979) observed that the deficit appeared independently of hippocampal damage. Also, in subsequent studies using rats with striatal lesions induced by kainic acid, but without any hippocampal damage, PA impairments were found using tasks involving the inhibition of learned (Pisa, Sanberg, \& Fibiger, 1978; Sanberg, 1978) or unpracticed (see Table 2) responses.

The majority of capsular fibers traversing the anterodorsal striatum of the rat are likely to be passing to or from the anterior cortex (Knook, 1965). It is interesting to note that Olmstead and Villablanca (1980) did not report any PA deficits for their groups with very large bilateral anterior cortex lesions. Therefore, in terms of Olmstead and Villablanca's own findings, damage to capsular fibers does not adequately explain the PA deficits found following electrolytic lesions of the striatum (Kirkby \& Kimble, 1968; Winocur, 1974).

We are not arguing here either that the anterior cortex is not involved in PA or that damage to capsu- lar fibers does not have behavioral consequences. Rather, the point is that the findings discussed above support the conclusion that damage to striatal neuronal tissue alone is sufficient to disrupt avoidance learning, including PA.

We have reviewed above those lesioning studies demonstrating impairments in PA; however, there is also extensive evidence of PA retention deficits following posttrial electrical stimulation of the striatum (e.g., Gold \& King, 1972; Kesner \& Wilburn, 1974; Wyers \& Deadwyler, 1971; Wyers, Deadwyler, Hirasuna, \& Montgomery, 1973; Zornetzer \& Chronister, 1973). These experiments concluded that the striatum was involved in aspects of acquiring and retaining a PA response.

\section{Some Theoretical Considerations}

Although the surgical technique adopted by Olmstead and Villablanca (1980) resulted in extremely large bilateral caudate nucleus lesions, it must be noted that the putamen remained intact. In strict neuroanatomical terms, there is no basis for their conclusion that the striatum, which consists of the caudate nucleus and putamen, is not involved in PA. While this point might seem pedantic, it has certain implications. It is quite likely that some studies that have shown PA deficits with lesions that involved the more ventral aspects of the striatum in the rat (Kirkby \& Kimble, 1968; Winocur, 1974) damaged tissue that is homologous to the putamen in the cat.

One of the problems with using extirpation techniques to investigate striatal involvement in PA is that, following caudate nucleus damage, an active reorganization of the brain might occur in response to the surgical insult (see Schoenfeld \& Hamilton, 1977). During the relatively long lesioning-testing interval ( 3 months) used by Olmstead and Villablanca, adaptive changes could have occurred in the caudatenucleus-damaged brains, minimizing the PA deficits.

There are numerous, and sometimes apparently conflicting, interpretations of striatal involvement in learned behavior (Polgar \& Kirkby, 1977). We agree with Olmstead and Villablanca (1980) that subjects with striatal damage can be characterized as showing heightened levels of reactivity to environmental and

Table 2

Effect of Bilateral Kainic Acid Lesions of the Striatum on Acquisition and Retention of a Step-Down Passive Avoidance Test

\begin{tabular}{|c|c|c|c|c|c|c|c|c|c|}
\hline \multirow[b]{2}{*}{ Group } & \multirow[b]{2}{*}{$\mathbf{N}$} & \multicolumn{2}{|c|}{$\begin{array}{c}\text { Initial } \\
\text { Step-Down } \\
\text { Latency } \dagger\end{array}$} & \multicolumn{2}{|c|}{$\begin{array}{l}\text { Time to } \\
\text { Criterion } \dagger\end{array}$} & \multicolumn{2}{|c|}{$\begin{array}{c}\text { Number of } \\
\text { Descents to } \\
\text { Criterion }\end{array}$} & \multicolumn{2}{|c|}{$\begin{array}{l}\text { 24-h Retention: } \\
\text { Step-Down } \\
\text { Latency } \dagger\end{array}$} \\
\hline & & Mean & SEM & Mean & SEM & Mean & SEM & Mean & SEM \\
\hline Control & 10 & 5.02 & 1.40 & 263.1 & 14.7 & 3.16 & .32 & 151.3 & 16.1 \\
\hline Kainic Acid Striatal & 10 & 6.62 & 1.73 & 394.2 & $28.3^{*}$ & 5.72 & $.63^{*}$ & 95.2 & $24.5^{*}$ \\
\hline
\end{tabular}

Note-The rats were lesioned as described in Sanberg (1980), which included pretreatment with diazepam to avoid hippocampal damage, and tested for PA as described in Sanberg et al. (1979). ${ }^{*}$ Significantly different from controls ( $p<.01$, two-tailed test). tIn seconds. 
physiological stimuli (Kirkby, 1973, 1976, 1798; Kirkby \& Polgar, 1974; Pisa et al., 1980; Polgar \& Kirkby, 1980; Sanberg et al., 1979). Therefore, it is possible that exaggerated arousal reactions may account for PA deficits in striatally lesioned animals. However, there are other possible interpretations of the PA deficits in animals with striatal lesions in terms of striatal involvement in memory functions (Pisa, Sanberg, \& Fibiger, 1981; Prado-Alcala \& Cobos-Zapiain, 1979; Prado-Alcala, Grinberg, Arditti, Garcia, Prieto, \& Brust-Carmona, 1975; Zornetzer \& Chronister, 1973). Therefore, the PA retention deficit in caudotomized adult cats in Olmstead and Villablanca's (1980) study could reflect a limited impairment in the retention of information for successful PA performance.

All the evidence reported here clearly implicates a role for the striatum in PA behavior. However, it is evident that further work is necessary to elucidate the underlying behavioral processes involved with striatal modulation of PA behavior.

\section{REFERENCES}

Cooper, B. R., Breese, G. R., Grant, L. D., \& Howard, J. L. Effects of 6-hydroxydopamine treatments on active avoidance responding: Evidence for involvement of brain dopamine. Journal of Pharmacology and Experimental Therapeutics, 1973, 185, 358-370.

Coyle, J. T., McGeer, E. G., McGeer, P. L., \& Schwarcz, R. Neostriatal injections: A model for Huntington's chorea. In E. G. McGeer, J. W. Olney, \& P. L. McGeer (Eds.), Kainic acid as a tool in neurobiology. New York: Raven Press, 1978.

Deadwyler, S. A., Montgomery, D., \& Wyers, E. J. Passive avoidance and carbachol excitation of the caudate nucleus. Physiology \& Behavior, 1972, 8, 631-635.

Fibiger, H. C., \& Phillips, A. G. Retrograde amnesia after electrical stimulation of the substantia nigra: Mediation by the dopaminergic nigro-neostriatal bundle. Brain Research, 1976, 116, 23-33.

Fox, S., Kimble, D. P., \& Lickey, M. E. Comparison of caudate nucleus and septal-area lesions on two types of avoidance behavior. Journal of Comparative and Physiological Psychology, 1964, 58, 380-386.

Glick, S. D., \& Greenstein, S. Comparative learning and memory deficits following hippocampal and caudate lesions in mice. Journal of Comparative and Physiological Psychology, 1973, 82, 188-194.

Gold, P. E., \& King, R. A. Caudate stimulation and retrograde amnesia: Amnesia threshold and gradient. Behavioral Biology, 1972, 7, 709-715.

Haycock, J. W., Deadwyler, S. A., Sideroff, S. I., \& McGaUGH, J. L. Retrograde amnesia and cholinergic systems in the caudate-putamen complex and dorsal hippocampus of the rat. Experimental Neurology, 1973, 41, 201-213.

Kesner, R. P., \& Wilburn, M. W. A review of electrical stimulation of the brain in context of learning and retention. Behavioral Biology, 1974, 10, 259-293.

KIRKBY, R. J. The caudate nucleus and arousal in the rat. Journal of Comparative and Physiological Psychology, 1973, 85, 82-96.

KIRKBY, R. J. Startle responsivity following telencephalic lesions in the rat. Physiological Psychology, 1976, 4, 383-386.

KIRKBY, R. J. Dorsal but not ventral lesions of the caudate nucleus disrupt maze learning in the rat. Physiology \& Behavior, 1978, 20, 669-672.

Kirkby, R. J., \& Kimble, D. P. Avoidance and escape behavior following striatal lesions in the rat. Experimental Neurology, 1968, 20, 215-227.

Kirkby, R. J., \& Polgar, S. Active avoidance in the laboratory rat following lesions of the dorsal and ventral caudate nucleus. Physiological Psychology, 1974, 2, 301-306.

KNook, H. L. The fibre-connections of the forebrain. Assen, The Netherlands: Van Gorcum, 1965.

Laursen, A. M. Conditioned avoidance behavior of cats with lesions in globus pallidus. Acta Physiologica Scandinavica, 1963, 57, 81-89.

Mitcham, J. C., \& Thomas, R. K. Effects of substantia nigra and caudate nucleus lesions on avoidance learning in rats. Journal of Comparative and Physiological Psychology, 1972, 81, 101-107.

Neill, D. B., Boggan, W. O., \& Grossman, S. P. Impairment of avoidance performance by intrastriatal administration of 6-hydroxydopamine. Pharmacology, Biochemistry and Behavior, 1974, 2, 97-103.

Neill, D. B., \& Grossman, S. P. Behavioral effects of lesions or cholinergic blockade of the dorsal and ventral caudate of rats. Journal of Comparative and Physiological Psychology, 1970, 71, 311-317.

Olmstead, C. E., \& Villablanca, J. R. Effects of caudate or frontal cortex ablations in cats and kittens: Passive avoidance. Experimental Neurology, 1980, 68, 335-345.

OLton, D. S. Shock-motivated avoidance and the analysis of behavior. Psychological Bulletin, 1973, 79, 243-251.

Pisa, M., Sanberg, P. R., \& Fibiger, H. C. Learning impairments in rats with experimental degeneration of the neostriatal neuropil. Society for Neuroscience Abstracts, 1978, 4, 48.

Pisa, M., Sanberg, P. R., \& Fibiger, H. C. Locomotor activity, exploration and spatial alternation learning in rats with striatal injections of kainic acid. Physiology \& Behavior, 1980, 24, 11-20.

Pisa, M., Sanberg, P. R., \& Fibiger, H. C. Striatal injections of kainic acid selectively impair serial memory performance in the rat. Experimental Neurology, in press.

Polgar, S., \& Kirkby, R. J. A model of neostriatal function. Australian Psychologist, 1977, 12, 73-74.

Polgar, S., \& Kirkby, R. J. The basal ganglia and pain mechanisms. In C. Peck \& M. Wallace (Eds.), Problems in pain. Sydney: Pergamon Press, 1980.

Prado-Alcala, R. A., \& Cobos-Zapiain, G. G. Interference with caudate nucleus activity by potassium chloride. Evidence for a 'moving' engram. Brain Research, 1979, 172, 577-583.

Prado-Alcala, R. A., Cruz-Morales, S. E., \& Lopez-Miro, F. A. Differential effects of cholinergic blockade of anterior and posterior caudate nucleus on avoidance behaviors. Neuroscience Letters, 1980, 18, 339-345.

Prado-Alcala, R. A., Grinberg, Z. J., Arditti, Z. L., Garcia, M. M., Prieto, H. G., \& Brust-Carmona, H. Learning deficits produced by chronic and reversible lesions of the corpus striatum in rats. Physiology \& Behavior, 1975, 15, 283-287.

Reyes-Vasquez, C., Zarco-Coronado, I., \& Brust-Carmona, H. Effects of intracaudate microinjections of 6-hydroxydopamine upon the suppression of lever pressing and upon passive avoidance conditioning in cats. Pharmacology, Biochemistry and Behavior, 1978, 9, 747-751.

Rothman, A. H., \& GLICK, S. D. Differential effects of unilateral and bilateral caudate lesions on side preference and passive avoidance behavior in rats. Brain Research, 1976, 118, 361-369.

SANBerg, P. R. An animal model of Huntington's disease: Behavioral, pharmacological and morphological changes following intrastriatal injections of kainic acid. Master's thesis, University of British Columbia, 1978.

SANBerg, P. R. Haloperidol-induced catalepsy is mediated by post-synaptic dopamine receptors. Nature, 1980, 284, 472-473.

Sanberg, P. R., Lehmann, J., \& Fibiger, H. C. Impaired learn- 
ing and memory after kainic acid lesions of the striatum: A behavioral model of Huntington's disease. Brain Research, $1978,149,546-551$.

Sanberg, P. R., Pisa, M., \& Fibiger, H. C. Avoidance, operant and locomotor behavior in rats with neostriatal injections of kainic acid. Pharmacology, Biochemistry and Behavior, 1979, 10, 137-144.

Schoenfeld, T. A., \& Hamilton, L. W. Secondary brain changes following lesions: A new paradigm for lesion experimentation. Physiology \& Behavior, 1977, 18, 951-967.

Thompson, R. L. Effects of lesions in the caudate nuclei and dorsofrontal cortex on conditioned avoidance in cats. Journal of Comparative and Physiological Psychology, 1959, 52, 650-659.

Thompson, R. L., \& Mettle R, F. A. Permanent learning deficit associated with lesions of the caudate nuclei. American Journal of Mental Deficiency, 1963, 67, 126-134.

Vasquez, F., Tellez, C., De la Mora, P., \& Brust-Carmona, $\mathrm{H}$. Modification of motor activity, passive avoidance conditioning and evoked potentials by microinjections of picrotoxin in both caudate nuclei in cats. Pharmacology, Biochemistry and Behavior, 1979, 11, 499-503.

Winocur, G. Functional dissociation within the caudate nucleus of rats. Journal of Comparative and Physiological Psychology, 1974, 86, 432-439.

Winocur, G., \& Mills, J. A. Effects of caudate lesions on avoidance behavior in rats. Journal of Comparative and Physiological Psychology, 1969, 68, 552-557.

Wyers, E. J., \& DEADWYLER, S. A. Duration and nature of retrograde amnesia produced by stimulation of caudate nucleus. Physiology \& Behavior, 1971, 6, 97-103.

Wyers, E. J., Deadwyler, S. A., Hirasuna, N., \& Montgomery, D. Passive avoidance retention and caudate stimulation. Physiology \& Behavior, 1973, 11, 809-819.

Zis, A. P., Fibiger, H. C., \& Phillips, A. G. Reversal by L-dopa and impaired learning due to destruction of the dopaminergic nigro-neostriatal projection. Science, 1974, 185, 960-962.

Zornetzer, S. F., \& Chronister, R. B. Neuroanatomical localization of memory disruption: Relationship between brain structure and learning task. Physiology \& Behavior, 1973, 10, 747-750.

(Manuscript received August 24, 1981; revision accepted for publication October $5,1981$. 